Temanummer: Spansk i Norge og det norske i den spansktalende verden.

\title{
“UN DÍA NORMAL EN MI VIDA" QUÉ Y CÓMO ESCRIBIMOS EN LA CLASE DE ESPAÑOL COMO LENGUA EXTRANJERA EN NORUEGA
}

\author{
Eli-Marie Danbolt Drange ${ }^{1}$ \\ Universitetet i Agder, Norge
}

\section{Sammendrag}

Denne artikkelen tar for seg ulike aspekter ved utviklingen av skriftlige ferdigheter i spansk blant norske elever. Artikkelen starter med å beskrive fremmedspråkenes posisjon i norsk skole generelt og situasjonen for spansk spesielt. Videre presenteres de skriftlige tekstene som analyseres og metoden som anvendes. De skriftlige tekstene er autentiske elevtekster samlet inn som en del av korpuset TRAWL (Tracking Written Learner Language). Analysen besvarer to hovedspørsmål: Hva og hvordan skriver elevene i spansk? Analysen av hva elevene skriver, viser at det første året på videregående skole skriver elevene stort sett tekster som handler om elevenes umiddelbare nærhet og dagligliv, der de mest frekvente ordene er verb og pronomen i første person entall. Andre året på videregående forbereder elevene seg på eksamen, og fokus flyttes fra personlige beskrivelser til tema knyttet til den spansktalende verden. Språket blir mer komplekst med bruk av bindeordene que og porque blant de mest frekvente ordene. En analyse av bruk av verb i fortid viser videre at elevene er i ferd med å tilegne seg verb i ulike tider, selv om den foretrukne tiden er presens perfektum. Her er det behov for mer omfattende studier for å se i hvilken grad elevene har tilegnet seg riktig bruk av de ulike verbtidene.

Palabras clave: Destrezas escritas; Español L2; Alumnos noruegos; Corpus de aprendices; Vocabulario; Verbos en pasado

\footnotetext{
${ }^{1}$ Eli-Marie D. Drange es profesora titular de lengua española de la Universidad de Agder, donde también es coordinadora de los estudios de español. Sus principales áreas de investigación son el habla coloquial y las variantes del español, la comunicación no verbal y diferentes aspectos relacionados con la enseñanza de español como lengua extranjera. Su último proyecto es ESIT (Elevspråk i transitt) que tiene como objetivo recopilar un corpus de textos escritos por alumnos noruegos en sus clases de lengua extranjera. Preside el grupo de investigación dedicado a la didáctica de lengua extranjera "Forum for fremmedspråksdidaktikk" y la revista Nordic Journal of Modern Language Methodology (http://journal.uia.no/index.php/NJMLM/index\#.WdkYODBx2DU), además de ser vicepresidenta de ANPE.
} 
Nordic Journal of Modern Language Methodology

2019, 7 (2), 6-27 Peer reviewed

Temanummer: Spansk i Norge og det norske i den spansktalende verden.

\section{Introducción}

El tema de este artículo es describir el desarrollo de las destrezas escritas de alumnos noruegos que aprenden español como lengua extranjera. Para estudiar este desarrollo, nos basamos en textos auténticos escritos por alumnos noruegos como parte de su enseñanza. Los textos han sido recopilados por el proyecto Tracking Written Learner Language (TRAWL), cuyo objetivo es establecer un corpus de aprendices de lengua extranjera en Noruega. Este estudio se ubica entonces en el marco de la lingüística de corpus, empleando la metodología asociada con esta rama de la lingüística. El corpus está en proceso de recopilación, por lo que los resultados presentados aquí son preliminares y principalmente descriptivos.

En primer lugar, queremos descubrir qué tipos de textos escriben los alumnos noruegos como parte de su enseñanza, y, en segundo lugar, queremos profundizar en cómo escriben. Para esta segunda parte, nos limitamos a estudiar el desarrollo del vocabulario y el desarrollo del uso de los verbos en pasado. Es importante recordar que el corpus está en proceso de recopilación, y el material empleado en este artículo se limita a textos de los dos primeros años del Bachillerato. Empezamos el artículo con una introducción al sistema educativo noruego y la enseñanza del español, para explicar el nivel de español de los alumnos estudiados. Seguimos con una presentación del proyecto TRAWL y el material de estudio antes de analizar el vocabulario y el uso de los verbos en pasados en los textos.

\section{La enseñanza de lengua extranjera en Noruega}

\section{La lengua extranjera en el sistema educativo noruego}

Los alumnos noruegos pueden elegir estudiar una tercera lengua cuando entran en la enseñanza secundaria básica llamada "ungdomsskolen" y empiezan en el octavo año de estudios. No es obligatorio elegir una tercera lengua, pero más del $80 \%$ de los alumnos eligen una de las opciones alemán, francés y español, y de éstas, el español es la lengua más popular (Udir). Al concluir la secundaria básica, los alumnos completan el nivel 1 de lengua extranjera, según el Currículo de lengua extranjera (Udir). Si siguen con la misma lengua en el Bachillerato, llegan a 


\section{Nordic Journal of Modern Language Methodology}

Temanummer: Spansk i Norge og det norske i den spansktalende verden.

completar el nivel 2 de esta lengua. Estos alumnos también tienen la opción de elegir profundización en la misma lengua extranjera el último año del Bachillerato, lo que significa completar el nivel 3 del Currículo.

No obstante, hay algunos alumnos que eligen una alternativa a lengua extranjera en la secundaria básica, y al seguir en el Bachillerato ${ }^{2}$, estos alumnos tienen que empezar con una lengua extranjera y estudiarla los tres años. Los alumnos que estudian lengua extranjera en la secundaria básica y optan por el Bachillerato, pueden continuar con la misma lengua dos años más o empezar con una nueva lengua. En la Tabla 1 se aprecian las opciones y los niveles de español que se adquieren con las diferentes opciones.

\begin{tabular}{|l|l|l|l|}
\hline Secundaria básica: & Opción 1 & Opción 2 & Opción 3 \\
\hline 8vo & Nivel 1: Español & Nivel 1: Otra LE & No tiene LE \\
\hline 9no & Nivel 1: Español & Nivel 1: Otra LE & No tiene LE \\
\hline 10mo & Nivel 1: Español & Nivel 1: Otra LE & No tiene LE \\
\hline Bachillerato: & Nivel 2: Español & Nivel 1: Español & Nivel 1: Español \\
\hline 1ro & Nivel 2: Español & Nivel 1: Español & Nivel 1: Español \\
\hline 2do & Nivel 3: Español & & Nivel 2: Español \\
\hline 3ro & & &
\end{tabular}

Tabla 1: Español como lengua extranjera en el sistema educativo noruego

El material que se estudia en este artículo se limita a alumnos de la opción 1 que han estudiado español en la secundaria básica y han completado el nivel 1 de español. Los textos se han recogido desde que empezaron en el primer año del Bachillerato hasta que cursan el segundo año del Bachillerato, marcado con negrita en la opción 1. El artículo estudia entonces el desarrollo del nivel 2 de la lengua.

En la secundaria básica, el examen final es un examen oral, lo cual indica que el objetivo principal de la enseñanza es desarrollar las destrezas orales. Después, al

2 Usamos el término Bachillerato cuando hablamos de «Videregående skole med studiespesialisering». 


\section{Nordic Journal of Modern Language Methodology}

Temanummer: Spansk i Norge og det norske i den spansktalende verden.

completar el nivel 2 de la lengua en el Bachillerato, se selecciona aleatoriamente a un porcentaje de alumnos para hacer un examen escrito nacional común para todo el país. Algunos de los alumnos restantes pueden ser seleccionados para presentar un examen oral. Por consiguiente, el patrón del examen escrito nacional puede influir en las prioridades que se hacen al desarrollar las destrezas escritas de los alumnos de español.

\section{La situación del español en la enseñanza}

El español como lengua extranjera en la escuela noruega es una asignatura relativamente joven. No fue hasta la introducción del nuevo currículo Kunnskapsløftet ${ }^{3}$ en 2006 que la asignatura del español despegó convirtiéndose en la lengua extranjera más popular y presente en la mayoría de los centros educativos en Noruega. Tal y como lo señala la investigadora Liv Eide (3/17) en un artículo sobre las creencias relacionadas con la asignatura del español, el crecimiento masivo del español resultó en una plantilla de profesores con limitada experiencia y competencia en la enseñanza de lengua extranjera. El resultado de esto es una asignatura que no se puede apoyar en largas tradiciones didácticas basadas en la investigación, y, por lo tanto, está en proceso de profesionalización.

Dentro de este marco, los manuales de español tienen una posición importante en la enseñanza del español en Noruega. Eide (3/17) indica que los manuales se pueden convertir en un ancla para los nuevos profesores que tratan de encontrar el camino en esta nueva asignatura, y la importancia de los manuales como fundamento para la enseñanza se comenta también en otros estudios de las prácticas docentes (Solfjeld, 5). Los planes del semestre recogidos en este proyecto confirman que, al planear la enseñanza, el manual se usa como un guía importante. Debido a esto, es importante tomar en cuenta los manuales que se usan en la enseñanza de ELE al estudiar los tipos de texto y el desarrollo del uso del pasado.

En las escuelas que participan en el proyecto, se usa principalmente el manual Vamos 1 de la editorial Cappelen Damm. Este manual existe en varias

\footnotetext{
3Se traduce como «Promoción de conocimiento».
} 


\section{Nordic Journal of Modern Language Methodology}

Temanummer: Spansk i Norge og det norske i den spansktalende verden.

ediciones, y en el material recopilado se usa tanto la edición de 2006 (Bugge et al.) como la edición revisada de 2012 (Bugge et al.). Los manuales se dividen en cuatro temas, que a su vez se dividen en cuatro capítulos (la edición de 2006) y cinco capítulos (la edición de 2012). El primer tema en ambos manuales enfoca el entorno del alumno e incluye datos personales, intereses y los estudios, funcionando como una repetición de lo que se ha estudiado en la secundaria básica. El segundo tema amplía el círculo y contiene temas como tiempo libre, salir a comer e ir de compras. Los dos últimos temas se relacionan con el mundo hispanohablante con presentaciones de destinos turísticos específicos y de aspectos culturales.

El vocabulario de cada capítulo se presenta como una lista alfabética de todas las palabras nuevas que aparecen en los textos, y las palabras más importantes están en negrita. Para un capítulo normalmente hay entre 50 y 80 palabras nuevas, pero en algunos capítulos hay hasta más de 100 palabras en la lista del vocabulario. El contenido gramatical se presenta de una manera normativa con referencia a las clases de palabras. El pretérito perfecto compuesto se suele introducir en la secundaria básica, y al seguir con español en el Bachillerato, normalmente se repite este tiempo del pasado en las primeras semanas de clase. Luego se introduce el pretérito perfecto simple, comúnmente denominado 'pretérito indefinido' al terminar el primer semestre del Bachillerato. Cuando se presenta un tema gramatical nuevo se enfatiza la forma del elemento gramatical, por ejemplo, en la introducción del pretérito perfecto simple se muestra la conjugación de los verbos regulares y los irregulares ser/ir y estar explicando que 'Cuando quieres contar algo que sucedió ayer, normalmente usas el indefinido.' (Bugge et al. 103, traducción mía). En los planes del semestre, los temas mencionados siguen el mismo orden de temas que el manual, así podemos usar la progresión del manual como punto de partida para estudiar el desarrollo de la lengua de los alumnos.

\section{TRAWL}

Para profundizar en el desarrollo de las destrezas escritas de los alumnos noruegos se ha creado el proyecto Tracking Written Learner Language (TRAWL) con 


\section{Nordic Journal of Modern Language Methodology}

Temanummer: Spansk i Norge og det norske i den spansktalende verden.

participación de Høgskolen i Innlandet, Universidad de Oslo, Universidad de Agder y Universidad de Trondheim (NTNU). El objetivo principal del proyecto es establecer un corpus longitudinal de textos escritos por alumnos noruegos en inglés y las lenguas extranjeras alemán, español y francés. La mayoría de los corpus de aprendices existentes han recopilado textos de estudiantes universitarios, de manera que un corpus de aprendices de alumnos entre 10-20 años es novedoso.

Los textos que se recopilan en el proyecto son textos escritos por los alumnos como parte de su enseñanza, por lo que son textos auténticos que ilustran cómo escriben los alumnos noruegos. El trabajo de recopilar textos está en desarrollo, y este artículo se basa en los primeros textos recogidos en español. El proyecto está aprobado por el Servicio Nacional de Datos de Investigación (NSD) y respeta el código ético de recopilación y almacenamiento de datos. Después de ser recopilados, los textos se digitalizan eliminando los datos que pueden identificar al alumno, y finalmente se codifican antes de integrarse al corpus digital.

\section{Material}

El material que se analiza en este artículo son textos libres escritos por alumnos en su primera prueba de español en el primer semestre del Bachillerato de tres institutos diferentes. Esta parte del material es el fundamento para describir el nivel de los alumnos al empezar el Bachillerato, específicamente el vocabulario utilizado y el uso de los verbos. La segunda parte del material consiste en la prueba final del primer semestre del segundo año de un instituto, con el que se mide el nivel alcanzado después de un año y medio de español en el Bachillerato. Como indica la Tabla 2 abajo, el material consiste en 64 textos. Aquí es importante subrayar que lo que se clasifica como un texto puede contener más de un texto, por ejemplo el texto del instituto 2 incluye tanto un texto informativo sobre Cuba como un relato personal sobre "Mi semana". Un texto se define entonces como una prueba escrita por un alumno en una fecha específica. La longitud de los textos varía mucho, hay textos de dos líneas y textos de 2-3 páginas, y como se ha indicado en la Tabla 2 el total de palabras recopiladas en este material es de casi 20000 palabras. Aunque es un 


\section{Nordic Journal of Modern Language Methodology}

Temanummer: Spansk i Norge og det norske i den spansktalende verden.

material limitado, los resultados pueden funcionar como un punto de partida para la reflexión y para, en el futuro, unos análisis más complejos sobre el material recopilado.

\begin{tabular}{|l|l|l|l|r|r|r|}
\hline Instituto & Semestre & Grupo & Texto & $\begin{array}{l}\text { Total } \\
\text { textos }\end{array}$ & $\begin{array}{l}\text { Total } \\
\text { palabras } \\
\text { diferentes }\end{array}$ & $\begin{array}{l}\text { Total } \\
\text { palabras }\end{array}$ \\
\hline Instituto 1 & $\begin{array}{l}\text { 1ro Nivel 2 } \\
\text { Semestre 1 }\end{array}$ & 1 & $\begin{array}{l}\text { Un día normal } \\
\text { en mi vida }\end{array}$ & 12 & 235 & 2050 \\
\hline Instituto 2 & $\begin{array}{l}\text { 1ro Nivel 2 } \\
\text { Semestre 1 }\end{array}$ & 2 & $\begin{array}{l}\text { Cuba y Mi } \\
\text { semana }\end{array}$ & 17 & 857 & 5438 \\
\hline Instituto 3 & $\begin{array}{l}\text { 1ro Nivel 2 } \\
\text { Semestre 1 }\end{array}$ & 3 & $\begin{array}{l}\text { Mi familia y mi } \\
\text { semana }\end{array}$ & 20 & 640 & 2993 \\
\hline Total 1ro Semestre 1 & \multicolumn{7}{l}{$\begin{array}{l}\text { Prueba de fin } \\
\text { de semestre }\end{array}$} & 15 & 1558 & 9244 \\
\hline Instituto 1 & $\begin{array}{l}\text { 2do Nivel 2 } \\
\text { Semestre 1 }\end{array}$ & 4 & $\mathbf{6 4}$ & $\mathbf{3 2 9 0}$ & $\mathbf{1 9 7 2 5}$ \\
\hline Total
\end{tabular}

Tabla 2. Descripción del material utilizado en el análisis

Para analizar el material, se han empleado las herramientas de \#LancsBox ${ }^{4}$, especialmente la herramienta Words que calcula la frecuencia de las palabras y la herramienta KWIC (Key Words in Context) que muestra la concordancia de la palabra que uno quiere estudiar, y que es una herramienta común en el análisis de corpus. Después de usar \#LancsBox, los datos de frecuencia se han exportado a una hoja de cálculo en Excel para hacer las listas de vocabulario y clases de palabras. Al estudiar la frecuencia de palabras, puede haber palabras que se repiten varias veces en el texto de un mismo alumno y que no se usan en los demás textos. Para el análisis se combina entonces el uso de herramientas que miden la frecuencia con muestras del contexto de las palabras para detectar este tipo de errores.

\section{¿Qué escribimos en las clases de español?}

Al empezar el Bachillerato, se suele usar el primer semestre para repetir y recordar los conocimientos de la lengua de la enseñanza secundaria, tal y como se ha

\footnotetext{
${ }^{4}$ Las herramientas se han bajado de: http://corpora.lancs.ac.uk/lancsbox/
} 
Temanummer: Spansk i Norge og det norske i den spansktalende verden.

señalado anteriormente. Este objetivo se manifiesta en las pruebas del primer semestre del Bachillerato que no presentan contenido nuevo. Las pruebas generalmente consisten en dos partes, una parte con ejercicios específicos de gramática y de comprensión de texto y otra parte con textos libres. Para el corpus se han recopilado los textos libres, y, como se muestra en la Tabla 2, los textos libres escritos por los alumnos en el primer semestre de español en el nivel 2 son muy similares y tratan el entorno de los alumnos. También vemos que el instituto 2 ha incluido dos tareas de escritura libre, donde el primer texto es un texto sobre Cuba y el segundo texto es sobre 'Mi semana'. El instituto 3 ha definido que el texto libre tiene que ser una presentación en un blog, y los alumnos empiezan el texto con un saludo. Las pruebas se han realizado sin ningún tipo de ayuda.

La prueba de fin del primer semestre del segundo año se basa en el examen escrito nacional del año 2015 (Utdanningsdirektoratet). Estos exámenes contienen normalmente cuatro ejercicios: el primer ejercicio consiste en una pregunta que requiere un pequeño texto como respuesta, el segundo ejercicio es de comprensión lectora y los dos últimos ejercicios son de redacción libre. Para este análisis se incluyen los tres textos de redacción, la primera pregunta se refiere a hacer planes de un viaje a América, en el segundo texto los alumnos tienen que terminar la historia del texto de comprensión lectora y para el último texto pueden elegir entre tres tareas relacionadas con los viajes y las aventuras. En contraste con los temas de los textos del primer semestre, los textos de redacción en el examen no enfatizan el entorno del yo, al contrario, invitan a la reflexión y a describir la vida de otras personas.

Para concluir la primera parte del análisis sobre qué escriben los alumnos de español, vemos que en el primer semestre de español los alumnos se concentran en el entorno personal describiendo su vida cotidiana. El género discursivo varía de un relato personal a una presentación en un blog. La única tarea que se aparta de este patrón es el texto informativo sobre Cuba con el título: ¿Qué sabes de Cuba? Como preparación para esta prueba, los alumnos tuvieron que elaborar un mapa mental sobre el tema que también pudieron llevar a la prueba. Por otro lado, en la prueba que se basa en un examen escrito nacional, el enfoque ha cambiado del entorno 


\section{Nordic Journal of Modern Language Methodology}

Temanummer: Spansk i Norge og det norske i den spansktalende verden.

personal del alumno hacia el mundo hispanohablante e invita a la reflexión y a la expresión de opiniones.

\section{¿Cómo escribimos en las clases de español?}

\section{El desarrollo del vocabulario en el primer año de Bachillerato}

La segunda parte del análisis se centra en cómo escriben los alumnos, con énfasis especial en el desarrollo del vocabulario y los verbos en pasado. Para poder decir algo sobre el desarrollo del vocabulario, empezamos a buscar las palabras más frecuentes en los textos recopilados. Es importante tomar en cuenta que el total de palabras en cada texto varía mucho, y como se vio en la Tabla 2, el total de palabras en el grupo de textos 1 es menor que en los otros grupos de textos. La razón de esto es que hay menos alumnos que han entregado este texto y el texto libre es más breve. En la Tabla 3 podemos ver las palabras más frecuentes en los tres grupos de textos y el número de veces que la palabra aparece en los textos. Las palabras en fondo blanco aparecen entre las 15 palabras más frecuentes en los tres grupos de textos, mientras las palabras con un fondo gris solo aparecen en dos de los tres grupos. Las palabras en negrita solamente aparecen en uno de los grupos de textos.

\begin{tabular}{|l|r|l|l|l|l|}
\hline $\begin{array}{l}\text { Grupo 1: } \\
\text { Un día normal }\end{array}$ & \multicolumn{2}{|l|}{$\begin{array}{l}\text { Grupo 2: } \\
\text { Cuba y mi semana }\end{array}$} & \multicolumn{2}{l|}{$\begin{array}{l}\text { Mrupo 3: } \\
\text { Mi familia y mi semana }\end{array}$} \\
\hline Palabra & Total ejemplos & Palabra & $\begin{array}{l}\text { Total } \\
\text { ejemplos }\end{array}$ & Palabra & Total ejemplos \\
a & 111 & y & 221 & y & 221 \\
\hline y & 106 & en & 168 & mi & 122 \\
\hline me & 92 & el & 157 & en & 96 \\
\hline mi & 73 & a & 151 & yo & 95 \\
\hline en & 61 & la & 143 & de & 68 \\
\hline el & 59 & es & 129 & con & 61 \\
\hline la & 58 & de & 117 & mis & $\mathbf{5 8}$ \\
\hline voy & 50 & Cuba & $\mathbf{1 1 4}$ & se & $\mathbf{5 6}$ \\
\hline de & 48 & he & 72 & es & 53 \\
\hline
\end{tabular}


Nordic Journal of Modern Language Methodology

2019, 7 (2), 6-27 Peer reviewed Temanummer: Spansk i Norge og det norske i den spansktalende verden.

\begin{tabular}{|l|r|l|r|l|r|}
\hline con & 37 & voy & 65 & he & 49 \\
\hline casa & $\mathbf{3 7}$ & las & 65 & me & 46 \\
\hline yo & 36 & con & 61 & tengo & $\mathbf{4 6}$ \\
\hline las & 34 & mi & 57 & semana & $\mathbf{4 4}$ \\
\hline después & 30 & un & 51 & una & $\mathbf{4 1}$ \\
\hline música & 28 & por & $\mathbf{5 0}$ & el & 40 \\
\hline
\end{tabular}

Tabla 3. Las 15 palabras más frecuentes los textos analizados

Si consideramos las 15 palabras más frecuentes en general, encontramos que casi todas las palabras son palabras funcionales: preposiciones, pronombres personales y de complemento, conectores y determinativos (artículos y posesivos). Los pronombres y los posesivos se refieren a la primera persona (yo, mi, mis, me) y confirman que la esfera tratada en el primer semestre trata del entorno del yo, lo cual también coincide con el primer tema del manual.

Hay pocas palabras de contenido, solo hay un par de verbos y sustantivos. Si consideramos los verbos, encontramos los verbos conjugados en la primera persona: voy, he y tengo, además del verbo ser en tercera persona: es. Las formas voy y he indican que los textos probablemente contengan información sobre los planes del alumno: voy + a + infinitivo, y de lo que el alumno ha hecho: he + participio. El contexto de los verbos se estudiará en la segunda parte del análisis.

En los textos del grupo 1 encontramos los sustantivos casa y música entre las 15 palabras más frecuentes. Ambas palabras hacen referencia al entorno personal del alumno, y una búsqueda del contexto de la palabra 'casa' indica que se usa en referencia a la casa del alumno con las expresiones 'voy a casa' y 'estoy en casa' como las más usadas:

\begin{tabular}{|l|l|l|}
\hline veces a la semana. Después, voy a & casa. & Me ducho y me como cena. \\
\hline recogida en <lugar>, y luego corro a & casa & para practicar. Ocho que estoy \\
\hline casa para practicar. Ocho que estoy en & casa. & Cuando lluega a casa tienda y \\
\hline que estoy en casa. Cuando lluega a & casa & tienda y el tren. Tengo un \\
\hline Despues tenemos un periodo libre. Voy a & casa & y yo como un poco comida. \\
\hline menos veinte y cinco. Voy a mi & casa & con el autobus y hago los \\
\hline
\end{tabular}




\section{Nordic Journal of Modern Language Methodology}

2019, 7 (2), 6-27 Peer reviewed

Temanummer: Spansk i Norge og det norske i den spansktalende verden.

\begin{tabular}{|l|l|l|}
\hline relajo en el sofa y estoy en & casa & para me arrastro en formación. \\
\hline las siete y media. Me voy a & casa & y co ceno con mi familia. \\
\hline termina a la dia voy en la & casa. & En mi casa visto la tele y \\
\hline dia voy en la casa. En mi & casa & visto la tele y como mucho \\
\hline
\end{tabular}

Tabla 4. Concordancia KWIC del contexto de 'casa' en los textos del grupo 1

La palabra música se puede usar en diferentes contextos, pero como vemos en el contexto de 'música' en figura 1, se trata igualmente del entorno del alumno.

colegio. Mientras voy al colegio escucho la música o hablo con mi amiga que se
pie a mi casa. Siempre escucho la música. Me gustan los tipos de música pop
la música. Me gustan los tipos de música popy hiphop. Cuando vuelvo a mi
asa hago mis deberes mientras escucho la música. Luego de o mientras hago mis deberes
voy con mis amigos ó escuho de música por ejemplo. Tomé viernes por ejemplo, entonces
Quizás yo veo la tele, escucho de música ó quizás juego PlayStation. Entonces voya

Figura 1. Concordancia KWIC del contexto de 'música' en los textos del grupo 1

Casa, música y después aparecen en los otros dos grupos de textos también, pero son menos frecuentes.

En los textos del grupo 2, 'Cuba' aparece entre las 15 palabras más frecuentes. No es de extrañar, ya que el primero de los dos textos libres es un texto informativo sobre Cuba. Si miramos los sustantivos más frecuentes en estos textos, encontramos varios sustantivos que se refieren a la presentación de un país, asimismo como palabras relacionadas con la vida diaria de los alumnos:

\begin{tabular}{|l|r|}
\hline Sustantivo & Total ejemplos \\
\hline cuba & 114 \\
\hline escuela & 20 \\
\hline amigos & 19 \\
\hline semana & 18 \\
\hline isla & 16 \\
\hline español & 16 \\
\hline noche & 15 \\
\hline ciencias & 15 \\
\hline
\end{tabular}




\section{Nordic Journal of Modern Language Methodology}

Temanummer: Spansk i Norge og det norske i den spansktalende verden.

\begin{tabular}{|l|r|}
\hline salsa & 14 \\
\hline lunes & 14 \\
\hline capital & 14 \\
\hline
\end{tabular}

Tabla 5. Los sustantivos más frecuentes en los textos del grupo 2

Un mapa de las palabras utilizadas en uno de los textos indica la variedad de palabras usadas en uno de los textos sobre Cuba:

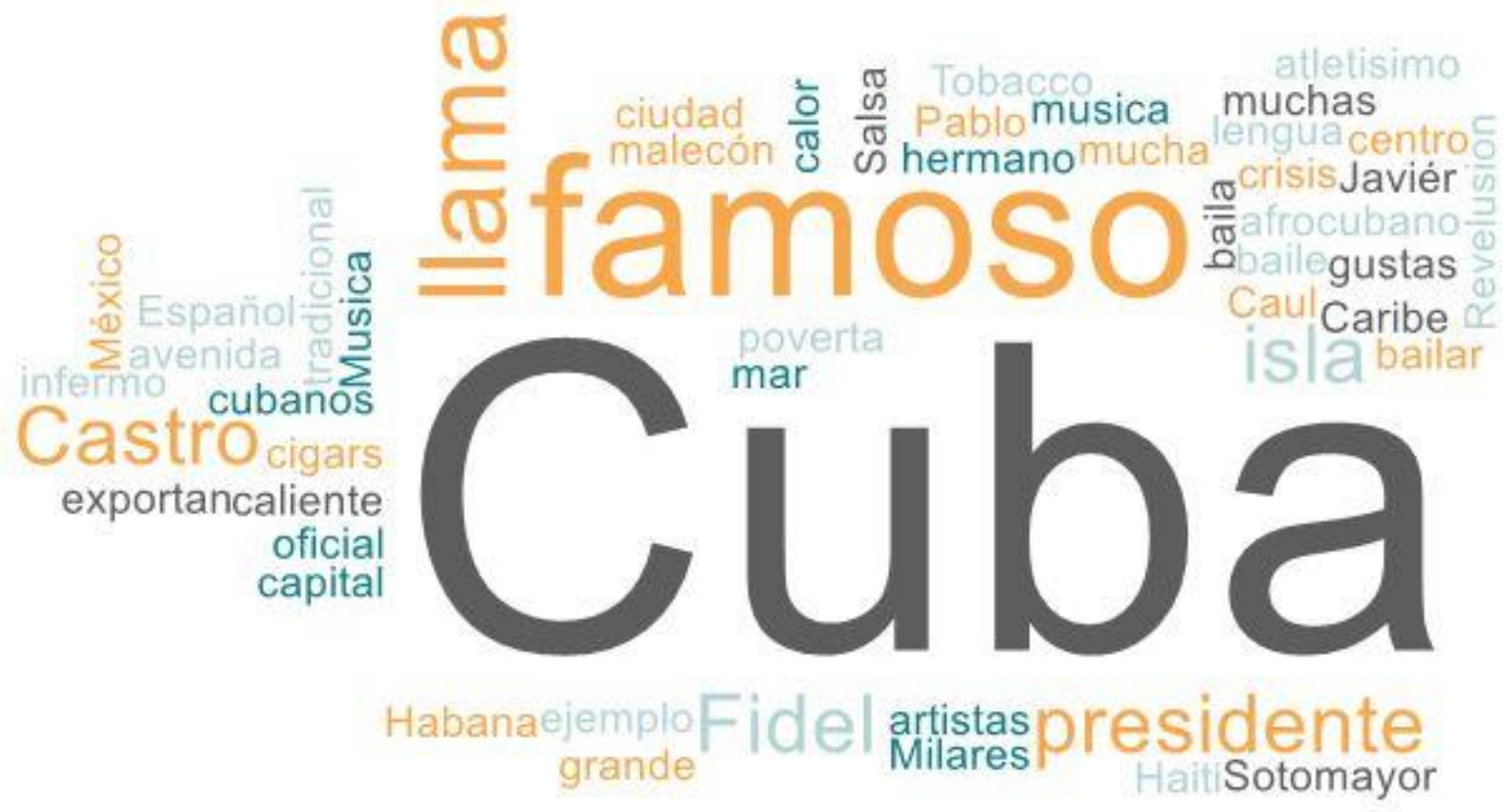

Figura 2. Mapa de palabras en uno de los textos sobre Cuba

El grupo 3 contiene cinco palabras que no aparecen en los dos otros grupos de textos: se, una, mis, tengo y semana. El pronombre se de tercera persona indica que el texto no solo trata del alumno, sino también de su familia. La búsqueda de concordancia KWIC de 'se' en los textos del grupo 3 muestra que todos los ejemplos de 'se' aparecen junto al verbo 'llamarse' o bien en tercera persona del singular o del plural, confirmando la referencia al entorno del alumno. 


\section{Nordic Journal of Modern Language Methodology}

Temanummer: Spansk i Norge og det norske i den spansktalende verden.

El verbo tengo también aparece en los otros dos grupos de texto, pero con menor frecuencia. El contexto del verbo tengo indica que este verbo se usa en diferentes combinaciones, como podemos ver en la búsqueda KWIC:

\begin{tabular}{|l|l|l|}
\hline ¡Hola! Me llamo <nombre>. & Tengo & diez y seis años. soy en noruega \\
\hline en noruega y vivo en <ciudad>. Yo & tengo & tres hermanos, cuatro gatos, una \\
\hline ¡Hola! Me llamo <nombre> y & tengo & dieciséis años. Soy de Noruega y \\
\hline ciudad está en el sur de Noruega. & Tengo & dos hermanas, una mayor y una \\
\hline pop. Esta semana yo he estudiado mucho, & tengo & tres pruebas! Yo no he dormido \\
\hline mucho, y en el fin de semana, & tengo & ganas de dormir muy mucho! En \\
\hline$<$ nombre> y mi padre se llama <nombre>. & Tengo & una hermana que se llama \\
\hline suéter. Y también quiero trabajar porque no & tengo & mucho dinero ahora. iAdiós! \\
\hline se llama <nombre> y <nombre>. También & tengo & un perro, que se llama <nombre>. \\
\hline Está en <ciudad> también. & Tengo & una madre y un padre. Mi padre \\
\hline y soy de <ciudad> en noruega. & Tengo & el pelo marrón y los ojos azules. \\
\hline
\end{tabular}

Tabla 6. Concordancia KWIC del contexto de 'tengo' en los textos del grupo 3

\section{El desarrollo del vocabulario en el segundo año de Bachillerato}

Para estudiar el desarrollo del vocabulario de los alumnos, es necesario comparar la frecuencia de las palabras en los primeros textos con la frecuencia de palabras en los textos del segundo año del Bachillerato, los textos del grupo 4. La Tabla 7 muestra las palabras más frecuentes del grupo 4 .

\begin{tabular}{|l|r|}
\hline Palabra & Total ejemplos \\
\hline y & 394 \\
\hline en & 279 \\
\hline de & 269 \\
\hline el & 204 \\
\hline la & 192 \\
\hline que & 184 \\
\hline
\end{tabular}




\section{Nordic Journal of Modern Language Methodology}

Temanummer: Spansk i Norge og det norske i den spansktalende verden.

\begin{tabular}{|l|r|}
\hline es & 166 \\
\hline a & 159 \\
\hline un & 140 \\
\hline muy & 122 \\
\hline una & 115 \\
\hline los & 113 \\
\hline no & 107 \\
\hline viajar & 106 \\
\hline porque & 98 \\
\hline
\end{tabular}

Tabla 7. Las palabras más frecuentes en los textos del grupo cuatro

Vemos que hay muchas palabras que coinciden en las dos listas de palabras, pero una diferencia importante es que en esta lista no hay ningún ejemplo de palabras relacionadas con la primera persona del singular (yo, me, mi). Otro aspecto interesante es que aquí encontramos los conectores que y porque, que indica que los alumnos escriben oraciones más complejas en este nivel.

El vocabulario estudiado en este apartado confirma que los primeros textos tratan el entorno del alumno, mientras los textos en el segundo año tienen un enfoque más abierto y oraciones más complejas.

\section{El desarrollo del uso del pasado}

\section{El uso de los verbos en pasado en el primer año de Bachillerato}

Como se ha señalado anteriormente, el pretérito perfecto compuesto se introduce normalmente en secundaria como el primer pasado que se aprende en español. También hemos indicado que en el primer semestre del Bachillerato se repiten los temas tratados en la secundaria básica, sin embargo, el pretérito perfecto compuesto no destaca como objetivo específico en los temas de los textos libres de la primera prueba que analizamos aquí. Tabla 8 indica las formas de los verbos más frecuentes en los tres grupos de textos: 


\section{Nordic Journal of Modern Language Methodology}

Temanummer: Spansk i Norge og det norske i den spansktalende verden.

\begin{tabular}{|l|r|l|l|l|r|}
\hline $\begin{array}{l}\text { Grupo 1: } \\
\text { Un día normal }\end{array}$ & \multicolumn{3}{l|}{$\begin{array}{l}\text { Grupo 2: } \\
\text { Cuba y mi semana }\end{array}$} & \multicolumn{2}{l|}{$\begin{array}{l}\text { Grupo 3: } \\
\text { Mi familia y mi semana }\end{array}$} \\
\hline Verbo & $\begin{array}{l}\text { Total } \\
\text { ejemplos }\end{array}$ & Verbo & $\begin{array}{l}\text { Total } \\
\text { ejemplos }\end{array}$ & Verbo & $\begin{array}{l}\text { Total } \\
\text { ejemplos }\end{array}$ \\
\hline voy & 50 & voy & 65 & es & 53 \\
\hline como & 24 & hay & 25 & he & 49 \\
\hline tengo & 23 & vamos & 21 & tengo & 40 \\
\hline hablo & 23 & tiene & 18 & llama & 33 \\
\hline escucho & 21 & tenido & 17 & quiero & 28 \\
\hline pongo & 17 & ha & 15 & vivo & 27 \\
\hline hago & 16 & comido & 15 & tiene & 23 \\
\hline entreno & 16 & llama & 14 & llamo & 12 \\
\hline vuelvo & 14 & tener & 14 & soy & 12 \\
\hline lavo & 9 & comer & 12 & llaman & 11 \\
\hline fui & 9 & hemos & 12 & gusta & comer \\
\hline ducho & 9 & Ir & 12 & comer & \\
\hline
\end{tabular}

Tabla 8. Los verbos más frecuentes en los textos analizados

Tanto en los textos del grupo 1 como del grupo 2, el verbo ir en primera persona del presente es el verbo más frecuente, y en ambos textos es mucho más frecuente que el verbo que le sigue en la lista. En los textos del grupo 2, voy se usa en 12 de los 17 textos, o sea que la mayoría de los alumnos usa este verbo. Una concordancia KWIC del verbo muestra que todos ejemplos excepto uno se usan para hablar de planes: lo que el alumno va a hacer el mismo día u otro día la misma semana. En el ejemplo que se distingue, el alumno usa la construcción voy a para explicar el objetivo del texto: "Voy a hablar un poco sobre mi semana" P60012_Y11. Este uso se puede clasificar como marcador discursivo usado para organizar el contenido del texto, un uso que también encontramos en dos de los textos del grupo 3: Primero voy a... / voy a hablar de. Estos ejemplos indican que se está creando una conciencia sobre la construcción de un texto, que es un objetivo importante en el desarrollo de las destrezas escritas en lengua extranjera.

En el grupo 1, todos los verbos están en primera persona del singular del presente, excepto fui que está en pretérito perfecto simple. El pasado no es un tiempo muy usado en estos textos, y una búsqueda de fui muestra que esta forma 


\section{Nordic Journal of Modern Language Methodology}

Temanummer: Spansk i Norge og det norske i den spansktalende verden.

del verbo aparece en tres textos diferentes, y en el contexto de este verbo encontramos otros verbos en pretérito perfecto simple. Podemos concluir que son pocos los alumnos que emplean este verbo en pasado, y los que lo hacen pueden tener un buen dominio del español. En la versión final del corpus habrá información sobre los conocimientos previos del español de cada alumno para ver si el dominio del español del alumno se puede explicar con esta información.

El grupo 2 tiene los participios tenido y comido además de las formas ha y hemos entre los verbos más frecuentes. La presencia de estos verbos nos indica que se usa el pretérito perfecto compuesto en los textos de estos alumnos, y la búsqueda de las formas diferentes del verbo haber muestra que se usa 137 veces en todos los textos. Aquí es importante recordar que esta búsqueda incluye el verbo haber como verbo impersonal en la forma hay o había, que se usa para hablar de Cuba. Sin embargo, la concordancia KWIC muestra que el pretérito perfecto compuesto se usa frecuentemente en los textos para hablar de lo que hacen los alumnos en la semana:

Ejemplo 1: El lunes me he levantado a las seis y media.

Ejemplo 2: En el lunes he ido colegio a las 9.45 y mi asignatura primera es Español.

En los verbos más frecuentes del grupo 3, por otra parte, no encontramos ningún participio, pero hay 49 ocurrencias del verbo haber en primera persona del presente: he. Encontramos esta forma del verbo en 16 de los 20 textos recogidos, así que más de la mitad de los alumnos han usado este tiempo. La búsqueda de concordancia KWIC muestra que el contexto más utilizado de he es "esta semana yo he", es decir que el pronombre de primera persona se usa junto al verbo. La Tabla 9 contiene algunos ejemplos de la concordancia de 'he'. 
Nordic Journal of Modern Language Methodology

2019, 7 (2), 6-27 Peer reviewed

Temanummer: Spansk i Norge og det norske i den spansktalende verden.

\begin{tabular}{|l|l|l|}
\hline rap más de pop. Esta semana yo & he & estudiado mucho, ¡tengo tres pruebas! \\
\hline itengo tres pruebas! ¡Yo no & he & dormido mucho, y en el fin de \\
\hline $\begin{array}{l}\text { viven cerca de mi casa. Esta } \\
\text { semana }\end{array}$ & he & entrenado balonmano con mis amigas. \\
\hline amigas. He estado en la escuela y & he & estudiado mucho. \\
\hline en la escuela y he estudiado mucho. & He & comido pizza porque me gusta mucho. Este \\
\hline ¡Hola! Me llamo <nombre> y & he & aquí mi blog. Primero voy a contar \\
\hline Primero esta semana yo & he & estudiado ciencias, he hecho tareas. \\
\hline Luego & he & estado con mi amigo <nombre $>$ \\
\hline Esta semana yo & he & comida mediodía en un restaurante con mi \\
\hline
\end{tabular}

Tabla 9. Concordancia KWIC del contexto de 'he' en los textos del grupo 3

En español no hace falta incluir el pronombre junto al verbo, y una búsqueda rápida del contexto de he en El Corpus del Español del Siglo XXI (CORPES XXI) solo muestra unos pocos ejemplos de yo junto a he. En noruego se necesita el pronombre junto al verbo, y se puede pensar que los alumnos incluyen el pronombre por influencia del noruego. Además de usar el pronombre de primera persona, muchos de los ejemplos incluyen la frase "esta semana". En el aprendizaje de una lengua extranjera es común aprender construcciones o frases fijas, y aquí intuimos una automatización de la construcción "esta semana yo he + participio". No tenemos los datos necesarios para saber si esta construcción se ha aprendido de esta manera, o si los alumnos la han creado ellos mismos.

En este momento del aprendizaje del español encontramos principalmente ejemplos de los verbos en pretérito perfecto compuesto cuando los alumnos hablan del pasado. No es de extrañar, porque según los manuales es el único tiempo aprendido hasta este momento. Ahora pasaremos a estudiar los verbos en pasado en los textos del grupo 4 del segundo año del Bachillerato para ver si hay un desarrollo en el uso de los verbos en pasado. 


\section{Nordic Journal of Modern Language Methodology}

Temanummer: Spansk i Norge og det norske i den spansktalende verden.

\section{El uso de los verbos en pasado en el segundo año de Bachillerato}

Para ver si hay un desarrollo en el uso de los verbos en pasado en los textos de los alumnos, estudiaremos ahora los textos del grupo 4 indicados en la Tabla 2. Como hemos mencionado anteriormente, estos textos son extraídos de un examen escrito de ámbito nacional de 2015, y que contiene tres textos diferentes de redacción libre. En Tabla 10 se han extraído las formas verbales de la lista de palabras más frecuentes en los textos del grupo 4.

\begin{tabular}{|l|r|}
\hline Verbo & Total ejemplos \\
\hline es & 166 \\
\hline viajar & 106 \\
\hline son & 43 \\
\hline era & 40 \\
\hline tiene & 38 \\
\hline ha & 38 \\
\hline fue & 36 \\
\hline han & 35 \\
\hline tienen & 33 \\
\hline tenía & 32 \\
\hline visitar & 29 \\
\hline
\end{tabular}

Tabla 10. Los verbos más frecuentes en los textos del grupo 4

En esta lista encontramos el verbo ser en presente, en pretérito imperfecto y en pretérito perfecto simple, y el verbo tener en presente y en pretérito imperfecto. Además, encontramos el verbo haber en sus formas ha y han. Según esta lista, los alumnos usan los tres tiempos pasados, pero necesitamos estudiar el contexto más detenidamente para ver si lo dominan.

La tarea 3 del examen invita a usar el pasado, especialmente el pretérito perfecto simple: 
Nordic Journal of Modern Language Methodology

Temanummer: Spansk i Norge og det norske i den spansktalende verden. ¿Cómo terminan las historias de Osvaldo y Alice? ¿Llegaron a sus destinos? ¿Qué pasó en sus viajes? Termina la historia de una de las personas y escribe un final feliz o infeliz. (Utdanningsdirektoratet)

El único verbo en pretérito perfecto simple en la Tabla 10 es fue, que encontramos en todos los textos excepto tres. Prácticamente todos los ejemplos de este verbo son respuesta a la tarea 3 , y en la captura de pantalla de la concordancia KWIC de fue en la Figura 3 podemos ver cómo se usa.

\begin{tabular}{|c|c|c|}
\hline 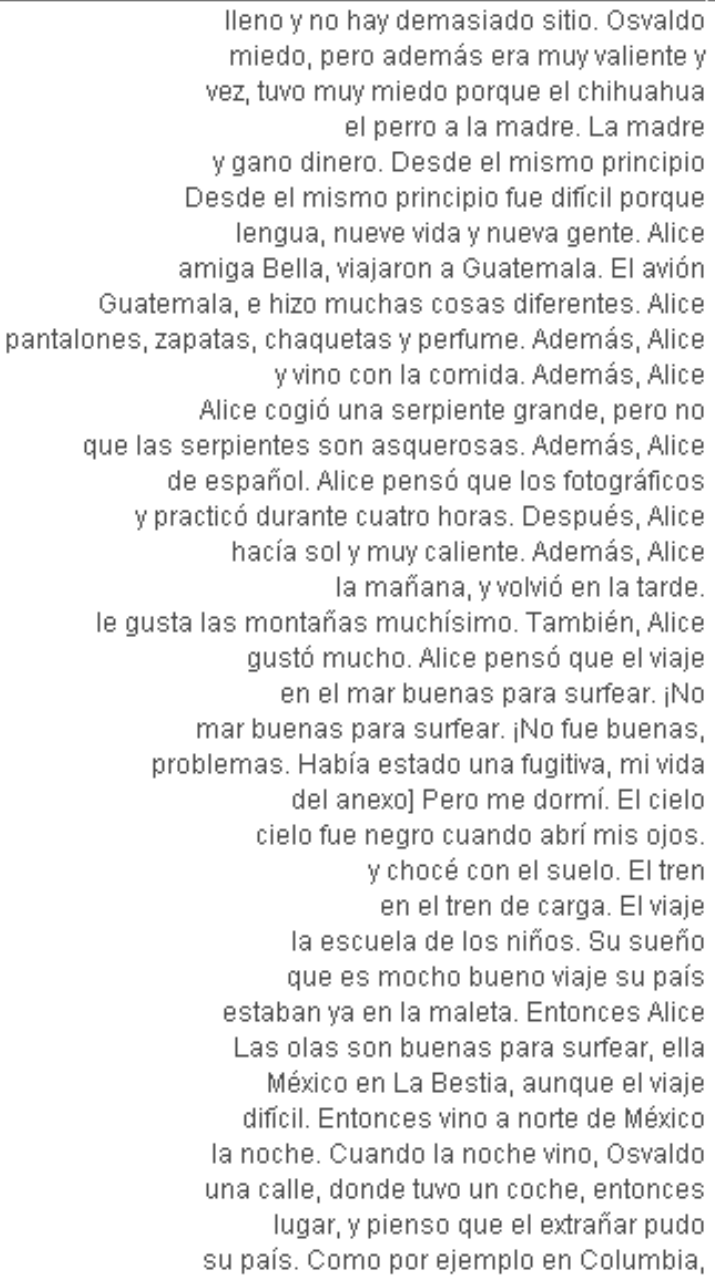 & $\begin{array}{l}\text { fue } \\
\text { fue } \\
\text { fue } \\
\text { fue } \\
\text { fue } \\
\text { fue } \\
\text { fue } \\
\text { fue } \\
\text { fue } \\
\text { fue } \\
\text { fue } \\
\text { fue } \\
\text { fue } \\
\text { fue } \\
\text { fue } \\
\text { fue } \\
\text { Fue } \\
\text { fue } \\
\text { fue } \\
\text { fue } \\
\text { fue } \\
\text { fue } \\
\text { fue } \\
\text { Fue } \\
\text { fue } \\
\text { fue } \\
\text { fue } \\
\text { fue } \\
\text { fue } \\
\text { fue } \\
\text { fue } \\
\text { fue } \\
\text { fue } \\
\text { fue } \\
\text { fue } \\
\text { fue }\end{array}$ & $\begin{array}{l}\text { a otro lugar, pero muchas personas peligrosas } \\
\text { adelante. Los chicos que estuvieron en el } \\
\text { muy tranquilo. Yo ayudé el perro y } \\
\text { muy feliz y me dio cien dólares. } \\
\text { dificil porque fue nueva lengua, nueve vida } \\
\text { nueva lengua, nueve vida y nueva gente. } \\
\text { vulnerables y débiles porque tenía miedo. A } \\
\text { a las } 14: 00 \text { por la mañana. Alice } \\
\text { a la ciudad por ir de compras. } \\
\text { al restaurante que se Ilama "Ristorante Guatemala", } \\
\text { a safari en Guatemala. Alice le gusta } \\
\text { peligroso. Alice estuve feliz por cogió la } \\
\text { en Lago Atitlán, que es muy bueno. } \\
\text { muy bueno. Siguiente, Alice llegó a Belice } \\
\text { a la playa, y estuve en la } \\
\text { en las montañas en Honduras. Despertó temprano } \\
\text { una grande experiencia, y Alice le gusta } \\
\text { en el teatro en Honduras, pero no } \\
\text { muy divertido. Tarea } 4 \text { Ventajas y desventajas } \\
\text { buenas, fue fantásticos! En la playa de } \\
\text { fantásticos! En la playa de surfear, conocí } \\
\text { estado muy diferente. Tarea } 4-\text { A ventajas } \\
\text { negro cuando abrí mis ojos. Fue noche } \\
\text { noche y hizo muy frío. Afortunadamente no } \\
\text { a fuera y estuve solo en el } \\
\text { muy frío, y duró tres dias. Cuando } \\
\text { Ileno. Anabel le ayudo que obtener su } \\
\text { suegro infeliz. Kilder: La migración ilegal } \\
\text { al aeropuerto y encontró sus amigos. Como } \\
\text { muy muy feliz. Esta es un sueño } \\
\text { muy dificil. Entonces vino a norte de } \\
\text { a la frontera, y esperó que la } \\
\text { listo para preparary claro para un } \\
\text { a una vida mejor. } 4 \text { ) ventajas y } \\
\text { grande. Además, lo pudo ser dificil adaptarse } \\
\text { un dictador que los colombianos no les }\end{array}$ \\
\hline
\end{tabular}

Figura 3. Concordancia KWIC de fue en los textos del grupo 4 
Temanummer: Spansk i Norge og det norske i den spansktalende verden.

Al estudiar los ejemplos, vemos que el verbo se usa tanto con el significado de ser como de ir, y que hay ejemplos donde se usa correctamente y otros ejemplos donde se usa el tiempo equivocado. El pretérito perfecto simple es un tiempo que los alumnos están en proceso de adoptar, pero que todavía no lo tienen integrado.

La Tabla 10 nos indica que la tercera persona del verbo ser en pretérito imperfecto: ERA es la forma en pasado más usada por los alumnos en estos textos. Encontramos este verbo en ocho de los 15 textos, lo que significa que más o menos de la mitad de los alumnos han escrito sus textos sin esta forma del verbo, mientras que la otra mitad la han integrado en su lengua. Al estudiar algunos ejemplos en contexto, vemos que se usa correctamente en muchos casos:

Ejemplo 3. porque Osvaldo no era un migrante legal.

Ejemplo 4. Lo que quería era ser un enfermero o un médico

Ejemplo 5. La vida era buenísima para Osvaldo ahora.

Ejemplo 6. Cuando Osvaldo era pequeño era flaco, pequeño y desnutrido

Al igual que el pretérito perfecto simple presentado arriba, los alumnos están en proceso de integrar esta forma verbal en su lengua, pero todavía no dominan ninguno de los dos tiempos. El extracto de uno de los textos indica también que el enfoque en el pretérito perfecto compuesto durante toda la enseñanza en la secundaria y al principio del Bachillerato influye en que en algunas situaciones se elige usar este tiempo sistemáticamente, aunque no es el tiempo más adecuado:

Ejemplo 7. El día siguiente ha estado el día último. Ha tenido el día a vacado de su problema. Pero, su plan no ha ido en la dirección bien. Cuando han llegado, no han llegado de feliz. Cuando han llegado han tenido una acogida mal, porque en llega finalmente se han estancado narcos y mafias. Todos migrantes han tenido miedo. Los narcos han sido grandes y lóbregos. Han agrupado los adultos y los niños en grupos diferentes. Los adultos han detenido, y sus niños también. Osvaldo, y los otras niños y personas menos de 18 años que han viajado solo no han arrestado. Los niños han ido y han vivido una vida nueva. 


\section{Nordic Journal of Modern Language Methodology}

Temanummer: Spansk i Norge og det norske i den spansktalende verden.

\section{Conclusiones}

Este artículo presenta un primer acercamiento al desarrollo de las destrezas escritas de los alumnos noruegos en su clase de español como lengua extranjera basándose en textos escritos por alumnos noruegos como parte del proyecto TRAWL. Los dos temas principales en el artículo son el desarrollo del vocabulario y del uso del pasado en los textos de alumnos en primero y segundo año de Bachillerato. Los resultados preliminares indican que el tipo de textos escritos al empezar en el Bachillerato invita a usar un vocabulario relacionado con el entorno personal del alumno y la vida cotidiana, mientras el ejemplo de textos del segundo año que se basa en un examen escrito nacional, muestra un cambio a un enfoque más abierto. La expresión de opinión y reflexión incluye el uso de conectores como que y porque, que también indica un dominio de oraciones más complejas.

En el desarrollo del uso del pasado, los textos del primer año del Bachillerato no contienen muchos ejemplos de verbos en pasado, y el único pasado aprendido en secundaria es el pretérito perfecto compuesto. Después de un año y medio de español, se espera que los alumnos escriban textos con el pretérito perfecto simple y el pretérito imperfecto también. El repaso de los textos muestra que los alumnos están usando verbos en los tres pasados, y que están en proceso de adquirir estos tiempos. Sin embargo, el tiempo preferido sigue siendo el pretérito perfecto compuesto y se usa sistemáticamente incluso en situaciones donde no es el tiempo adecuado en español. Un estudio más amplio de los usos del pasado podrá indicar en qué situaciones se usan correctamente los verbos y en qué situaciones es más difícil usar el tiempo correcto.

\section{Bibliografía}

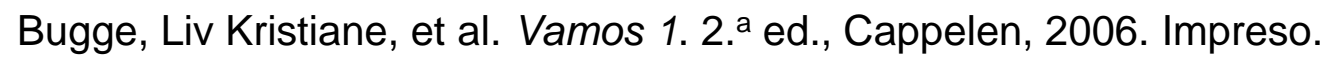

Bugge, Liv Kristiane, et al. Vamos 1. 2. ${ }^{\text {a }}$ ed., Cappelen Damm, 2012. Impreso.

Eide, Liv. «Forestillinger om spanskfaget: et kritisk blikk på lærebøker i spansk». Acta Didactica Norge, vol. 7, $\mathrm{n}^{\circ}$ 1, 2013, pp. 1-17, doi: http://dx.doi.org/10.5617/adno.1111. Web. 9 de dic. 2018. 


\section{Nordic Journal of Modern Language Methodology}

Temanummer: Spansk i Norge og det norske i den spansktalende verden.

Real Academia Española: Banco de datos (CORPES XXI) [en línea]. Corpus del Español del Siglo XXI (CORPES). http://www.rae.es. Web. 25 de mayo. 2018.

Solfjeld, Kåre. Andre fremmedspråk på ungdomstrinnet - med praktisk tilnærming. 1, Fremmedspråksenteret., 2007, https://fremmedspraksenteret.no/neted/upload/attachment/site/group55/FPS o nline 1 2007.pdf. Web. 9 de dic. 2018.

Utdanningsdirektoratet. Eksamen FSP5095/PSP5051/FSP5098 Spansk nivå II/I+II Elever og privatister. Oslo: Utdanningsdirektoratet, 20 de mayo de 2015. Impreso.

Utdanningsdirektoratet,

Grunnskolens

Informasjonssystem: https://gsi.udir.no/app/\#!/view/units/collectionset/1/collection/77/unit/1/. Web. 6 de marzo. 2018a.

Utdanningsdirektoratet, Læreplan i fremmedspråk. https://www.udir.no/kl06/FSP1-01. Web. 12 de marzo. 2018b. 